Revista de Lenguas para Fines Específicos

\title{
Estudio sectorial de formación y cualificación en lengua inglesa en la familia profesional de química
}

\author{
Nicolás Montalbán Martínez ${ }^{1}$ [1] https://orcid.org/0000-0002-0425-840X \\ Universidad de Murcia
}

Avda. Teniente Flomesta, $5 \cdot 30003 \cdot$ Murcia (Spain)

\section{Article history}

Paper received: 8 March 2017 Paper received in revised form and accepted for publication: 22 January 2019

\section{Keywords}

didactics of the English language, English for Specific Purposes, needs analysis
ABSTRACT

The aim of this research is to detect needs and tendencies in English language training and qualification in Spain within the framework of the Chemical industry. This work employs a descriptive analysis method with a qualitative approach. A questionnaire was prepared and posted to a representative sample of the Chemical industry. From that study, some relevant information was achieved on:

- Identifying characteristics of the companies

- Use of the English language

- Analysis of the current training and possible improvements

The results of this work will be used to improve, in a second research, the existing training in English for Specific Purposes (ESP) within the framework of the Chemical industry.

\section{RESUMEN}

El propósito de este trabajo es realizar un estudio de las necesidades y tendencias de la formación en lengua inglesa en el sector de la industria química. Para ello se empleó un método de análisis descriptivo con un enfoque cualitativo. Se elaboró una encuesta que fue enviada a una muestra representativa de la industria química. Gracias a este estudio, se conocieron datos relevantes en torno a:

- Características identificativas de las empresas

- Uso de la lengua inglesa

- Análisis de la formación actual y posibles mejoras 
Los resultados de esta investigación se utilizarán para, en un segundo estudio y partiendo de la formación existente, mejorar la propuesta formativa existente en inglés para fines específicos (IFE) en el entorno de la industria química.

\section{Introduction}

\subsection{Orígenes del IFE.}

El término IFE fue introducido por Crystal (1995:108) para designar la lengua empleada por hablantes de distintas lenguas. Existen una serie de razones que han motivado de forma poderosa la introducción de IFE en la actualidad.

La primera de estas razones sería el proceso de globalización que comenzó, sobre todo, en 1945, a finales de la Segunda Guerra Mundial. En esta época hubo una expansión notable de la ciencia, la tecnología, y la economía a escala planetaria. Esta expansión motivó la demanda de una lengua internacional, que el poder económico de EE.UU. orientó hacia el inglés.

Otro factor a considerar sería la aparición de novedosas teorías en el ámbito de la Lingüística. Durante los años sesenta los análisis existentes de IFE, se basan en los registros, es decir, una variedad idiomática en la que destacan una serie de características gramaticales y léxicas que muestran una cierta regularidad. De ahí que los materiales empleados para la enseñanza de IFE estén fundamentados en aspectos sobre todo morfosintácticos, obviándose aspectos comunicativos y de uso de la lengua, tan explotados en nuestros días. Al principio este IFE se entendía como ICT (Inglés para Ciencia y Tecnología), IFA (Inglés para Fines Académicos), e incluso IFO (Inglés para fines Ocupacionales), de acuerdo con Hutchinson and Waters (1987). De su importancia puede dar fe la siguiente reseña (Alcaraz Varó 2000:16): "(...) se puede afirmar que el inglés con fines específicos es hoy una disciplina académicamente reconocida y alentada por organismos internacionales, como la UNESCO o The British Council (Piqué y otros, 1994:57) y, como tal disciplina, constituye el núcleo de una gran número de cursos impartidos a universitarios y a profesionales". Para llegar a este estado de la cuestión se pasó por una fase en la que Widdowson (1978) habla sobre un uso lingüístico sobre la forma, y Trimble (1990) se refiere a la retórica como un proceso empleado para producir un texto concreto, todo ello en la década de los 70.

A principios de los 80 tres nuevos enfoques en torno a la enseñanza de IFE vieron la luz, el primero centrado en el aprendizaje (Dudley-Evans \& St John: 1998), un segundo basado en el desarrollo de las destrezas comunicativas, y el tercero en el análisis de la situación meta. A finales de los 80 asistimos a una clara división entre el Inglés Profesional y el Inglés Académico. En la actualidad, debido a los fenómenos de globalización y de desarrollo de las TIC (Tecnologías de la Información y la Comunicación) el IFE ha tenido un desarrollo extraordinario, dando especial énfasis a los métodos interactivos. Otra apreciación, resultado de las investigaciones, fue la constatación de las enormes diferencias entre los lenguajes específicos, no usando los mismos registros un químico que un ingeniero. 
En relación con el apartado anterior, se desarrollan nuevos enfoques en la psicología educacional focalizándose en la importancia de las necesidades del alumno, teniendo en cuenta sus intereses, y dándole un papel fundamental a la motivación. Crystal (1995:108) alude a «un curso cuyo contenido se termina en función de las necesidades profesionales del alumno»). Incluso Robinson (1991) atiende a características a partir de las necesidades de los alumnos, y la selección de destrezas y habilidades en torno a estas necesidades y el tiempo disponible.

Sysoyve (2000) sugiere que el desarrollo de un curso de IFE debe considerarse como un proceso en el que se contemplan modificaciones, para acomodarse a las necesidades e intereses de los alumnos. Hadley (2006:3) ha afirmado que «la clave para enseñar IFE es centrarse en lo específico». El IFE se refiere a las necesidades específicas de los alumnos por un lenguaje específico. Para Mackay y Mounford (1978:4) el IFE es «la única forma en la que podemos entender la noción de lenguaje especializado como un repertorio restringido de palabras y expresiones, seleccionadas de todo el idioma que se usan y determinado por el contexto, la tarea o la vocación». El análisis de las necesidades no puede separarse del desarrollo de los materiales y programaciones, especialmente en IFE. En este sentido, Basturkmen (2017: 17) afirma que el análisis de las necesidades es la identificación del lenguaje y destrezas, empleadas para determinar y seleccionar materiales de aprendizaje basados en IFE. Este análisis de la necesidad se puede emplear también para evaluar a los alumnos, así como el proceso de aprendizaje al final de todo el proceso. Para Nunan (2004), el proceso por medio del cual se obtiene información acerca de las necesidades de los alumnos es el análisis de las necesidades.

Recientes estudios (Liu, Chan, Yan, and Sun, 2011; Basturkmen, 2010: 17), siguen insistiendo en la división entre IFA, e IFE, dependiendo de la finalidad de I acción formativa. En cuanto a la enseñanza del léxico en IFE, existen trabajos sobre el aprendizaje de vocabulario específico en ingeniería, centrados en el estudio de corpus, concretamente en el análisis de lenguaje auténtico en contextos especializados. Entre estos contextos podemos destacar las presentaciones en congresos (RowleyJolivet, 2015), artículos de investigación (Kanoksilapatham, 2015), reuniones profesionales (Spence \& Liu, 2013), e investigaciones relativas a necesidades de vocabulario de alumno de L2 (Ward, 2009). Todas estas investigaciones abundan en el hecho de la enorme brecha existente entre las necesidades de vocabulario de alumnos de L2, y las demandas reales de varios campos de la ingeniería. Hsu (2014) sugirió que para tener una buena comprensión de un texto de ingeniería, un alumno de L2 necesitaría conocer 5.000 familias léxicas, nombres propios, compuestos, abreviaturas, etc. Para acometer tan ingente tarea, hay autores que han desarrollado listas de vocabulario derivadas de corpus especializados. Estos corpus están basados en su frecuencia de aparición (Hsu, 2014; Todd, 2017; Ward, 2009). Aunque no hay una única forma de seleccionar vocabulario para EFE, es posible considerar algunos métodos, como por ejemplo el de Kwary (2011). Este autor proporcionó una visión de los métodos existentes, conjuntamente con el software capaz de identificar vocabulario técnico, clasificarlo, analizar las palabras clave, etc. Existen programas informáticos con software gratuito para realizar la selección de vocabulario, por ejemplo AntConc (Anthony, 2014), Compleat Lexical Tutor (Cobb, 2015), y Range (Heatley, Nation, \& Coxhead, 2002).

\section{Metodología}


2.1 Análisis de la situación los subsectores en los que existen necesidades de formación en lengua inglesa.

El método que se llevó a cabo para realizar esta investigación fue un análisis descriptivo con un enfoque cualitativo. Para tener un conocimiento preciso de la situación, se elaboró un formulario (Tabla 1) en una página web alojada en un servidor de Hosting, con la finalidad de recoger los datos adecuados a las preguntas formuladas. De estos resultados se emitirá un informe final. Las preguntas son impersonales, no habiendo en dicho formulario preguntas personales ni almacenamiento de datos sensibles. Este cuestionario se envió a empresas, adheridos y asociaciones pertenecientes a FEIQUE (Federación Empresarial de la Industria Química Española), que representa a la mayoría del sector, en septiembre de 2012. De acuerdo con los datos ofrecidos por su página web (https://www.feique.org/conocenos/), FEIQUE representa a la industria química española, «un sector estratégico para la economía española integrado por 3.300 empresas que, con una facturación anual de 65.647 millones de euros, genera el 13,4\% del Producto Industrial Bruto, y 670.000 puestos de trabajo en España. El sector químico es el segundo mayor exportador de la economía española y el primer inversor industrial en I+D+I y en protección del medio ambiente». Además de FEIQUE, el cuestionario se envió a empresas, asociaciones empresariales, e institutos tecnológicos no pertenecientes a este organismo, por medio de conversación telefónica, entrevista personal con personal relevante, y escrutinio de páginas web. Las preguntas del cuestionario están referidas a:

- características de las empresas (preguntas 1-5)

- uso de la lengua inglesa (preguntas 6-15)

- análisis de la situación actual de la formación en lengua inglesa y posibles mejoras (preguntas 16-20)

\begin{tabular}{|c|c|c|}
\hline Características de las empresas & Uso de la lengua inglesa & $\begin{array}{l}\text { Análisis de la situación actual de la } \\
\text { formación en lengua inglesa y posibles } \\
\text { mejoras }\end{array}$ \\
\hline 1. Sector de producción & $\begin{array}{l}\text { 6. Departamentos en los que se } \\
\text { emplea la lengua inglesa }\end{array}$ & $\begin{array}{l}\text { 16. Existencia de programa de formación } \\
\text { continuada en inglés }\end{array}$ \\
\hline 2. Comunidad Autónoma & $\begin{array}{l}\text { 7. Grado de conocimiento del } \\
\text { idioma }\end{array}$ & $\begin{array}{l}\text { 17. Importancia de la implementación de } \\
\text { la lengua inglesa }\end{array}$ \\
\hline $\begin{array}{l}\text { 3. Número de puestos de trabajo totales en la } \\
\text { empresa }\end{array}$ & $\begin{array}{l}\text { 8. Estimación del volumen de } \\
\text { negocio reservado al comercio en } \\
\text { lengua inglesa }\end{array}$ & $\begin{array}{l}\text { 18. Para qué se considera necesaria la } \\
\text { lengua inglesa }\end{array}$ \\
\hline $\begin{array}{l}\text { 4. Desglose de puestos de trabajo por } \\
\text { departamentos }\end{array}$ & $\begin{array}{l}\text { 9. Frecuencia de viajes a países en } \\
\text { los que es necesaria la lengua } \\
\text { inglesa }\end{array}$ & $\begin{array}{l}\text { 19. Qué se debería mejorar en la } \\
\text { formación }\end{array}$ \\
\hline \multirow[t]{5}{*}{ 5. Ubicación de los trabajadores } & 10. Perspectivas futuras & $\begin{array}{l}\text { 20. Existencia de certificación externa del } \\
\text { nivel de inglés }\end{array}$ \\
\hline & $\begin{array}{l}\text { 11. Documentos relacionados en } \\
\text { inglés }\end{array}$ & \\
\hline & $\begin{array}{l}\text { 12. Estimación del uso del } \\
\text { teléfono en inglés }\end{array}$ & \\
\hline & $\begin{array}{l}\text { 13. Entrevistas personales en } \\
\text { inglés }\end{array}$ & \\
\hline & $\begin{array}{l}\text { 14. Empleo de terminología } \\
\text { específica inglesa en el proceso } \\
\text { productivo }\end{array}$ & \\
\hline
\end{tabular}


Tabla 1. Preguntas de la encuesta

\section{Resultados}

3.1 Cuestionario 1: Encuesta web para determinar las necesidades de formación en inglés dentro del ámbito de FEIQUE.

La encuesta fue enviada a 30 empresas, 4 adheridas y 19 asociaciones (Anexo 1) (https://www.feique.org/servicios-a-los-asociados/ - 1465832933047-c2fd9e80-1eac), miembros de FEIQUE, en total 53, en septiembre de 2.012. De esas 53, obtuvimos respuesta de 44, con lo se tiene un porcentaje alto de participación del $83,0188 \%$. A continuación se expresa en figuras y tablas los resultados obtenidos.

3.1.1 Análisis del Cuestionario 1: Características identificativas de las empresas.

\begin{tabular}{|l|l|}
\hline Datos & $\begin{array}{l}\text { - Los sectores participantes mayoritarios recogidos en este } \\
\text { cuestionario representan a fabricantes de Productos químicos básicos, } \\
\text { industria farmacéutica y productos de limpieza doméstica e industrial } \\
\text { (un 70\% del total). }\end{array}$ \\
\hline Índices & $\begin{array}{l}\text { - Se entiende un Universo suficientemente homogéneo y } \\
\text { representativo con cuyos índices puedan estar recogidas y consideradas } \\
\text { la totalidad de las empresas de este sector laboral. }\end{array}$ \\
\hline
\end{tabular}

Tabla 2. Generalidades y rasgos comunes: Empresas por sectores participantes en la encuesta web.

\begin{tabular}{|l|l|}
\hline Datos & $\begin{array}{l}\text { - Las comunidades autónomas más participativas en las respuestas del } \\
\text { cuestionario, salvo excepciones, son indicativas de la incidencia de este } \\
\text { sector productivo respecto de la actividad laboral general. } \\
\\
\text { - Cataluña, Región de Murcia, País Vasco y Comunidad de Madrid, por } \\
\text { este orden, han sido los territorios más señalados. }\end{array}$ \\
\hline Índices & $\begin{array}{l}\text { - Cada territorio puede reconocer la incidencia laboral del sector en } \\
\text { base a estadística recogidas en Asociaciones Empresariales, Cámaras de } \\
\text { Comercio, Institutos tecnológicos, altas en el IAE, etc. }\end{array}$ \\
\hline
\end{tabular}

Tabla 3. Generalidades y rasgos comunes: Empresas por Comunidades Autónomas participantes en la encuesta web. 


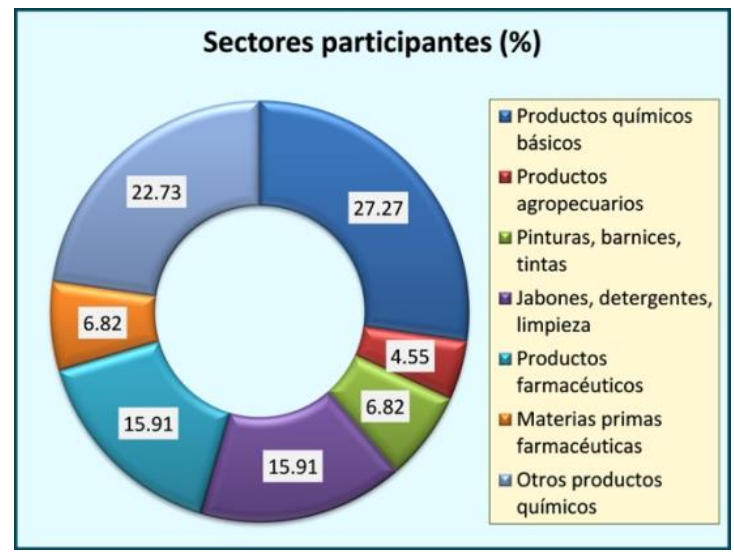

Figura 3. Porcentajes de empresas por sectores participantes en la encuesta web (diagrama de sectores).

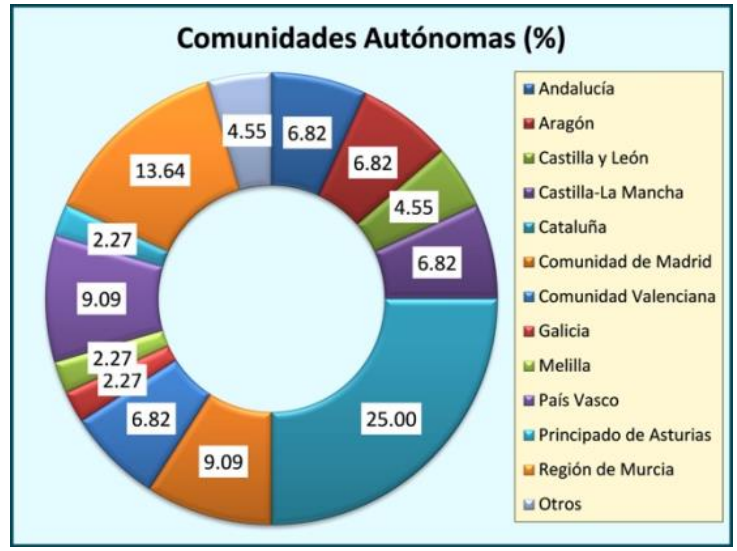

Figura 4. Porcentajes de empresas por Comunidades Autónomas participantes en la encuesta web (diagrama de sectores).

\subsubsection{Análisis del Cuestionario 1: Uso de la lengua inglesa.}

\begin{tabular}{|l|l|}
\hline Datos & - Los departamentos de ventas/compras y administración constituyen \\
& los de máximo porcentaje (en torno al 50\%) de puestos que requieren \\
& conocimiento de la lengua inglesa. \\
& - Por otra parte cerca del 50\% de trabajadores de las empresas ejercen \\
& sus tareas profesionales fuera del territorio nacional, reservando, \\
& siempre según las empresas, un 80,23\% de dominio de la lengua inglesa \\
& sobre otros idiomas. \\
& - La media de puestos que requieren conocimiento de la lengua \\
& inglesa en la empresa es de 36,54\% \\
\hline Índices & $\begin{array}{l}\text { - Se necesita facilitación en la comunicación empresa-clientes- } \\
\text { proveedores. }\end{array}$ \\
& $\begin{array}{l}\text { - Sobre un universo de 500000, representa } 182700 \text { puestos en que es } \\
\text { necesaria formación inicial para acceder al mercado laboral }\end{array}$ \\
\hline
\end{tabular}

Tabla 4. Generalidades y rasgos comunes: Departamentos empresariales en los que es necesario el inglés y comparación con otros idiomas. 


\begin{tabular}{|l|l|}
\hline Datos & $\begin{array}{l}\text { - El nivel de conocimiento por necesidad en el dominio de la lengua } \\
\text { inglesa es mayoritario }(>55 \%) \text { en lo que se denomina 'independiente'. } \\
\text { Los niveles 'básico' y 'muy competente' son cuantitativamente similares. }\end{array}$ \\
\hline Índices & - Necesidad de conocimiento mayoritario en un nivel medio-alto. \\
\hline
\end{tabular}

Tabla 5. Generalidades y rasgos comunes: Grado de conocimiento del inglés en las empresas.

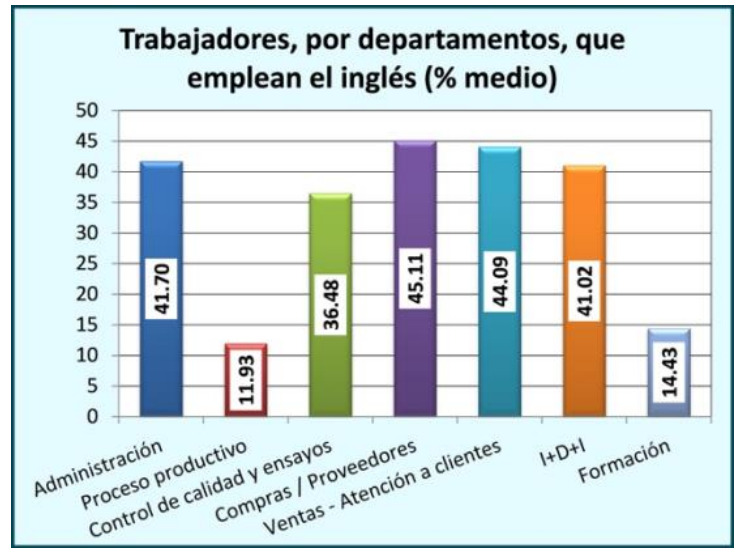

Figura 5. Porcentajes de trabajadores, por departamentos, que emplean el inglés (diagrama de barras).

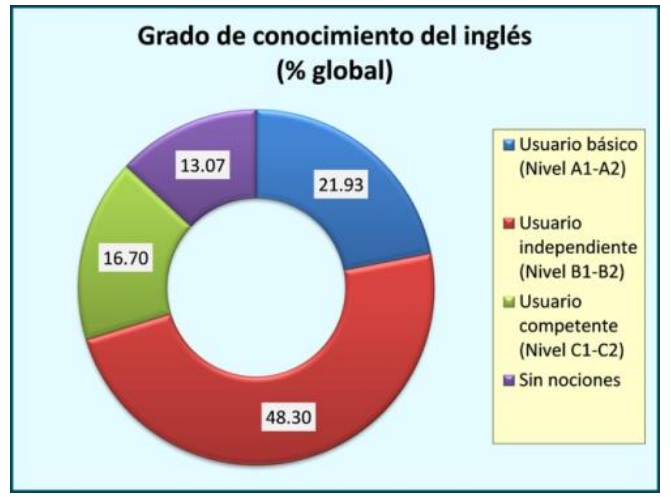

Figura 6. Porcentaje del grado de conocimiento del inglés diagrama de sectores).

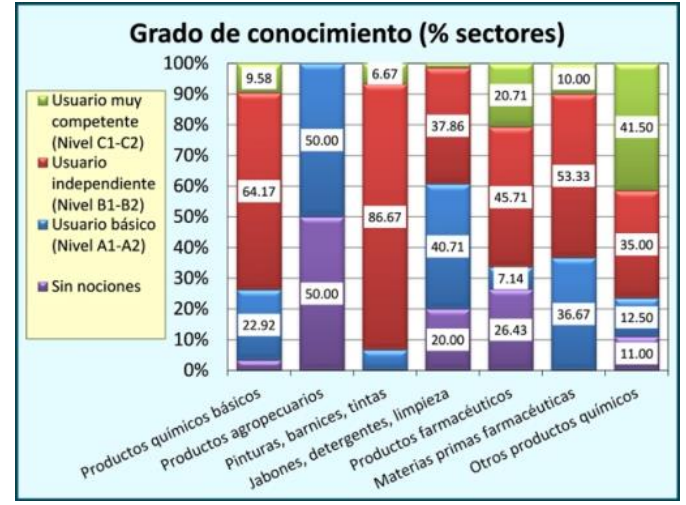

Figura 7. Porcentaje del grado de conocimiento del inglés (diagramas de barras) por sectores. 


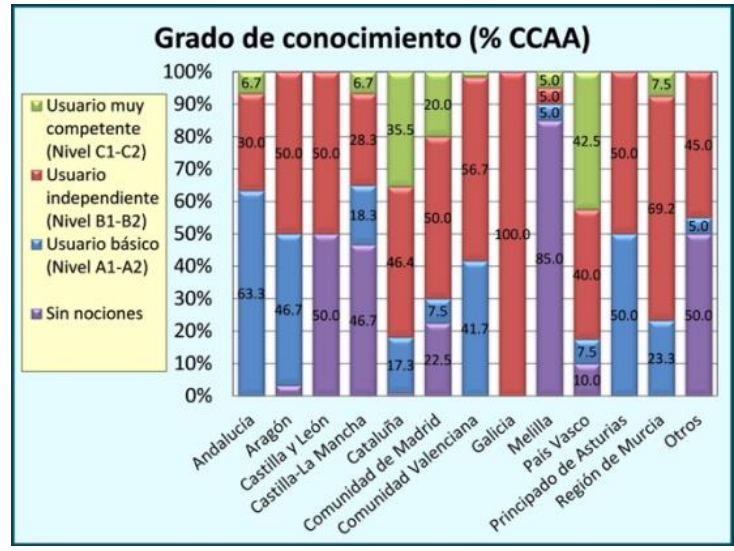

Figura 8. Porcentaje del grado de conocimiento del inglés (diagramas de barras) por Comunidades Autónomas.

\begin{tabular}{|l|l|}
\hline Datos & $\begin{array}{l}\text { - Los datos arrojan elevados índices de interrelación } \\
\text { con el mercado exterior. La media está en torno al } 40 \% \\
\text { destacando por encima las comunidades de Cataluña, } \\
\text { Galicia, Murcia y País Vasco. }\end{array}$ \\
\hline Índices & $\begin{array}{l}\text { - Alta incidencia de la oferta empresarial vía páginas } \\
\text { web, estructuras organizativas de comercio exterior, } \\
\text { confederaciones empresariales, etc. }\end{array}$ \\
\hline
\end{tabular}

Tabla 6. Generalidades y rasgos comunes: Volumen de negocio reservado al comercio en inglés.

\begin{tabular}{|l|l|}
\hline Datos & $\begin{array}{l}\text { - La mayoría de las empresas responden de su acreditación bajo normas de } \\
\text { calidad y gestión (UNE-EN-ISO 9001, UNE-EN-ISO 17025) y, en menor medida, } \\
\text { Gestión ambiental (UNE-EN-ISO 14001). }\end{array}$ \\
\hline Índices & $\begin{array}{l}\text { - Toda la normalización citada rige en España, la Unión Europea y, por otra } \\
\text { parte, tiene alcance universal, las relaciones contractuales de las empresas de } \\
\text { ámbito internacional, quedan obligadas en su seguimiento y, por tanto, en la } \\
\text { relación de los idiomas matrices implicados. }\end{array}$ \\
\hline
\end{tabular}

Tabla 7. Generalidades y rasgos comunes: Acreditación de las empresas bajo norma.

\begin{tabular}{|l|l|}
\hline Datos & $\begin{array}{l}\text { - Los viajes al extranjero constituyen una actividad operativa creciente para } \\
\text { favorecer las acciones e incidencia en el mercado exterior. } \\
\end{array}$ \\
$\begin{array}{l}\text { - Es convicción general (por encima del } 53 \% \text { de las respuestas) que la } \\
\text { movilidad en el comercio exterior irá en aumento. }\end{array}$ \\
\hline $\begin{array}{l}\text { Índices } \\
\text { los viajes de negocios. } \\
\\
\text { acciones formativas que satisfagan las necesidades previstas. }\end{array}$ \\
\hline
\end{tabular}

Tabla 8. Generalidades y rasgos comunes: Viajes de empresa a países en que es necesario el inglés y expectativas futuras de viajes. 


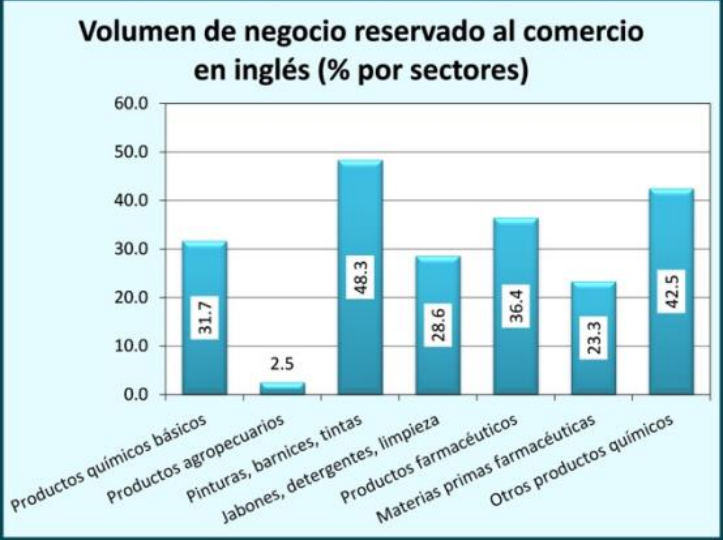

Figura 9. Porcentaje del volumen de negocio reservado al comercio en inglés por sectores.

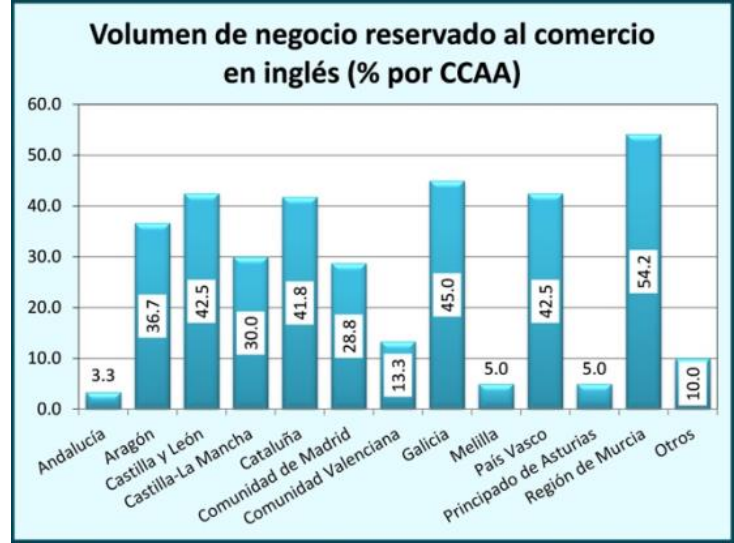

Figura 10. Porcentaje del volumen de negocio reservado al comercio en inglés por Comunidades Autónomas.

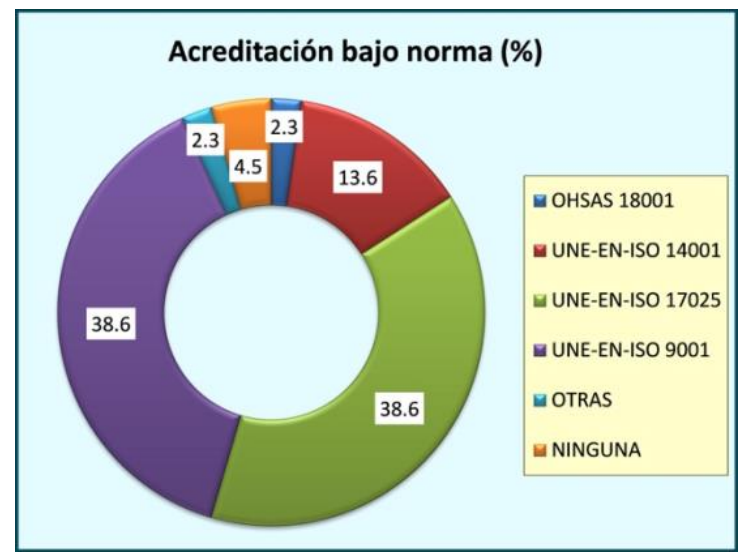

Figura 11. Porcentaje de acreditación bajo norma (diagrama de sectores). 


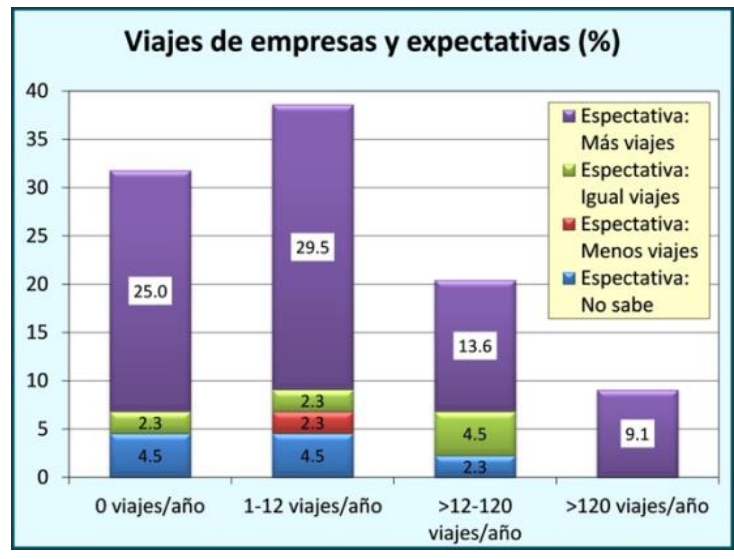

Figura 12. Frecuencia de viajes/año, a países en que es necesario el inglés, y expectativas futuras de viajes (diagrama de barras).

\begin{tabular}{|l|l|}
\hline Datos & $\begin{array}{l}\text { - La lectura y redacción de manuales, cartas, informes, e-mails, así } \\
\text { como mantener una conversación fluida queda patente de manera } \\
\text { especial, respuestas de este cuestionario, en los departamentos de } \\
\text { administración y comerciales de las empresas química. }\end{array}$ \\
\hline Índices & $\begin{array}{l}\text { - Las acciones formativas podrían estar específicamente orientadas, } \\
\text { aparte del componente idiomático de corte 'doméstico', hacia los } \\
\text { componentes relativos al 'argot' químico y a su faceta administrativa. }\end{array}$ \\
\hline Índices & $\begin{array}{l}\text { - Atender el volumen de negocio en lengua inglesa es crítico para } \\
\text { la supervivencia de la actividad y el desarrollo empresarial cara al } \\
\text { futuro. }\end{array}$ \\
\hline
\end{tabular}

Tabla 9. Generalidades y rasgos comunes: Elaboración de documentos empresariales en inglés.

\begin{tabular}{|c|c|}
\hline Datos & $\begin{array}{l}\text { Dos de cada tres empresas disponen de página WEB en lengua } \\
\text { inglesa. }\end{array}$ \\
\hline Índices & $\begin{array}{l}\text { - Tanto para exponer la oferta comercial, la actividad 'on -line' como la } \\
\text { presencia en foros de investigación y debate técnico, las empresas creen } \\
\text { conveniente mayoritariamente disponer de una ventana abierta al mundo } \\
\text { en un código común: la lengua inglesa. } \\
\text { - Se considera que el empleo de otro idioma distinto, restringe en } \\
\text { mucho el alcance en la interrelación empresarial. }\end{array}$ \\
\hline
\end{tabular}

Tabla 10. Generalidades y rasgos comunes: Páginas web de empresas en inglés. 


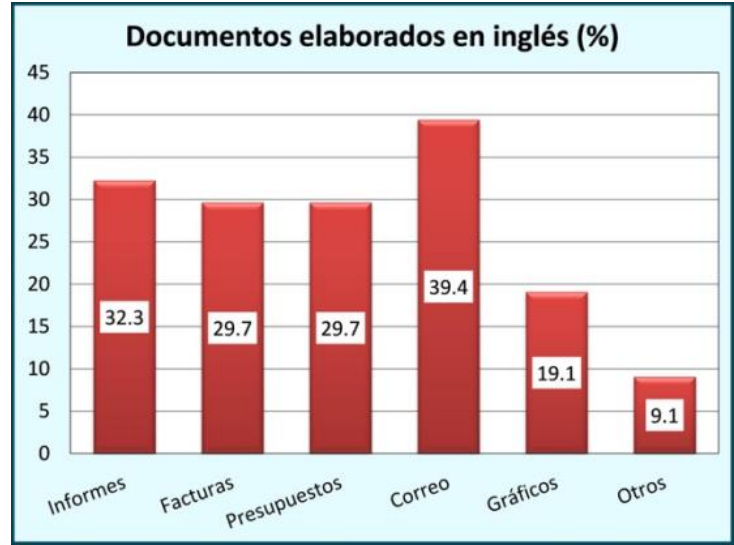

Figura 13. Porcentaje de documentos elaborados en inglés (diagrama de barras).

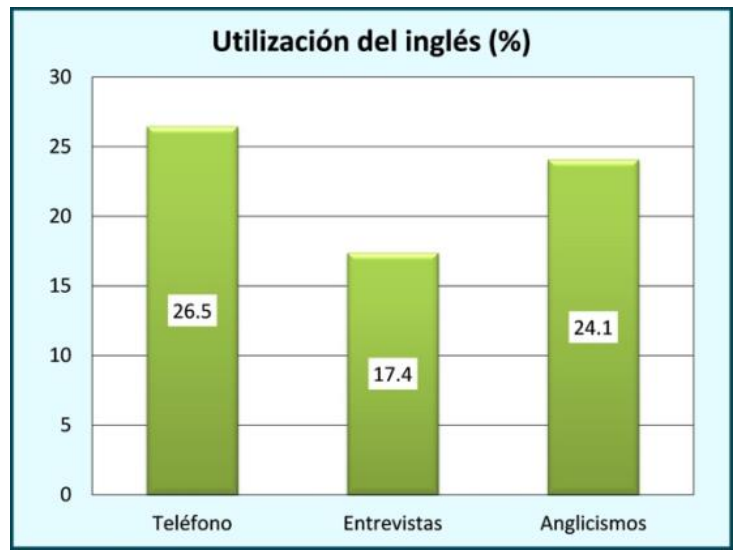

Figura 14. Porcentajes de utilización del inglés: por teléfono, en entrevistas y empleando anglicismos (diagrama de barras).

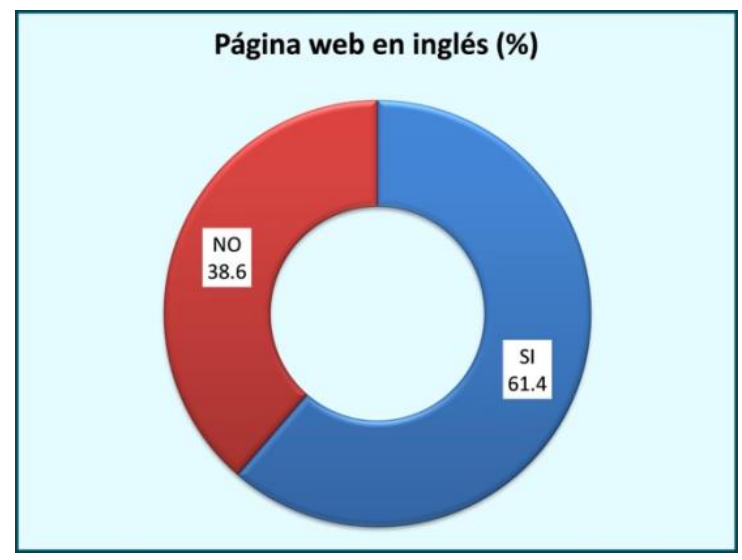

Figura 15. Porcentaje de existencia de página web en inglés (diagrama de sectores). 


\subsubsection{Análisis del Cuestionario 1: Formación.}

\begin{tabular}{|l|l|}
\hline Datos & $\begin{array}{l}\text { - Sólo el } 60 \% \text { de respuestas dispone de programa anual de } \\
\text { formación, del cual, el } 20 \% \text { atienda la necesidad formativa en lengua } \\
\text { inglesa. Se puede hablar de un 12\% en relación con el idioma inglés. }\end{array}$ \\
\hline Índices & $\begin{array}{l}- \text { Cruzado el dato con la necesidad de acciones formativas en inglés, } \\
\text { donde se revela un } 80 \% \text { en la necesidad de acciones formativas } \\
\text { urgentes en lengua inglesa, aparece un déficit neto a atender en } \\
\text { torno al } 65 \% .\end{array}$ \\
\hline
\end{tabular}

Tabla 11. Generalidades y rasgos comunes: Programas de formación continuada en inglés en las empresas.

\begin{tabular}{|c|c|}
\hline Datos & $\begin{array}{l}\text { - Un } 58 \% \text { de empresas considera apremiante la programación de } \\
\text { acciones formativas en lengua inglesa. } \\
\text { - En torno al } 80 \% \text { considera que la necesidad de implementar } \\
\text { acciones formativas en lengua inglesa es muy necesaria y } \\
\text { extremadamente urgente. }\end{array}$ \\
\hline Índices & $\begin{array}{l}\text { - Las empresas consideran que un mayor adiestramiento en lengua } \\
\text { inglesa favorece las expectativas de promoción en el volumen de } \\
\text { negocio. } \\
-\quad \text { La oferta formativa es insuficiente. }\end{array}$ \\
\hline Datos & $\begin{array}{l}\text { La oferta formativa en lengua inglesa es considerada insuficiente } \\
\text { en un } 32.56 \% \text {. }\end{array}$ \\
\hline Índices & $\begin{array}{l}\text { El } 32.56 \text { de las necesidades de formación y complementos } \\
\text { formativos de los } 182700 \text { puestos que precisan adiestramiento en } \\
\text { lengua inglesa. }\end{array}$ \\
\hline
\end{tabular}

Tabla 12. Generalidades y rasgos comunes: Ofertas lingüísticas en inglés y necesidad de implementar acciones formativas en las empresas.

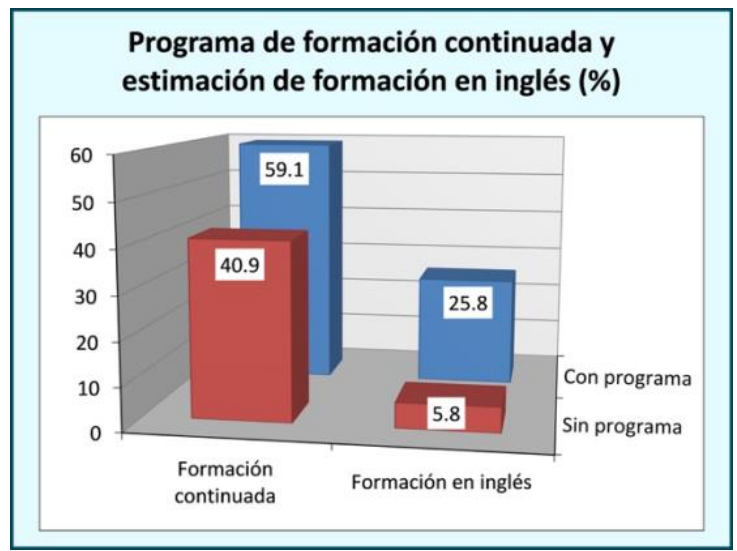

Figura 16. Porcentajes de empresas que disponen de un programa de formación continuada y en inglés (diagrama de barras). 


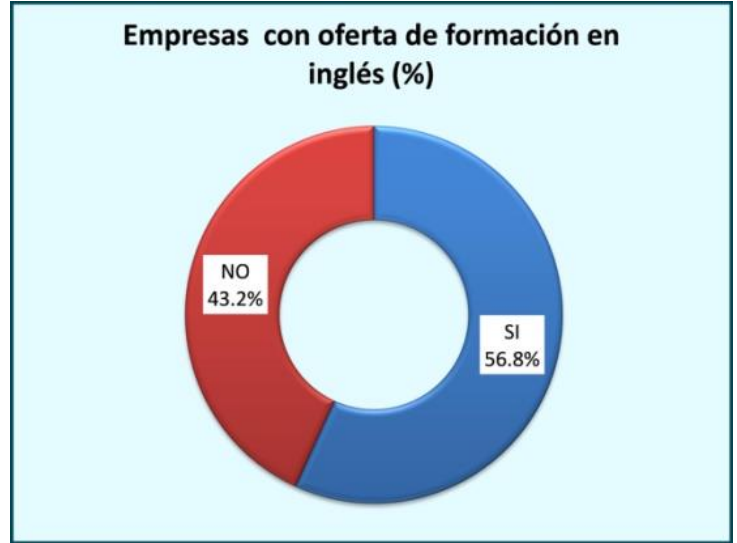

Figura 17. Porcentaje de empresas con oferta lingüística de inglés (diagrama de sectores).

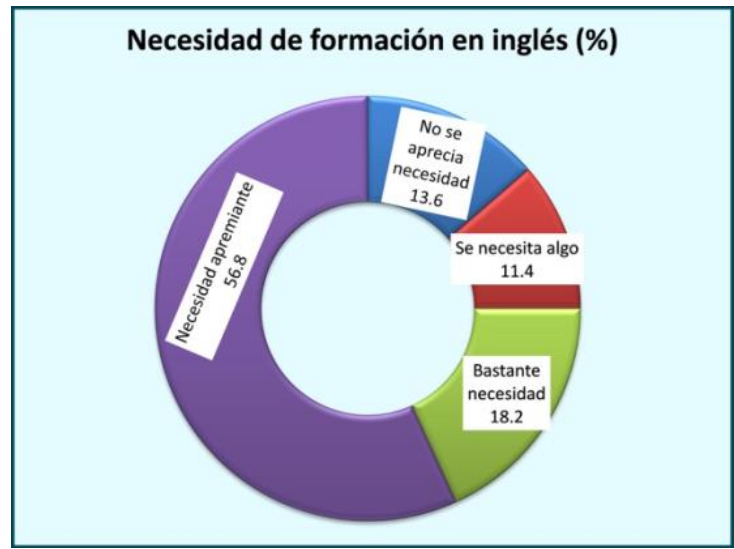

Figura 18. Porcentaje de necesidad de formación en inglés que tienen las empresas (diagrama de sectores).

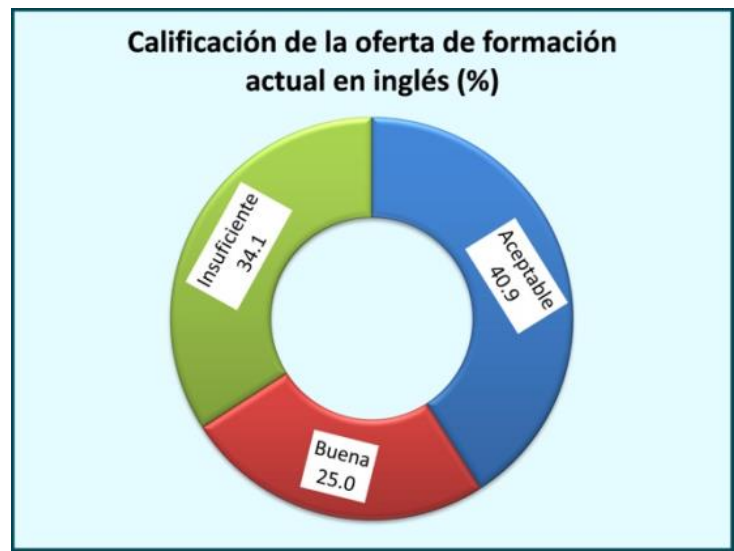

Figura 20. Calificación de las empresas de las ofertas de formación en inglés (diagrama de sectores). 


\begin{tabular}{|l|l|}
\hline Datos & $\begin{array}{l}\text { - Casi el } 100 \% \text { de las respuestas abundan en la convicción de que el } \\
\text { horizonte laboral inmediato en el sector químico, está condicionado por } \\
\text { el conocimiento de la lengua inglesa. }\end{array}$ \\
\hline Índices & $\begin{array}{l}\text { - El mercado está cada vez más globalizado. La actividad química en } \\
\text { sus facetas técnica, normativa, comercial, administrativa, etc. }\end{array}$ \\
\hline
\end{tabular}

Tabla 13. Generalidades y rasgos comunes: Importancia del inglés para encontrar trabajo en la industria química.

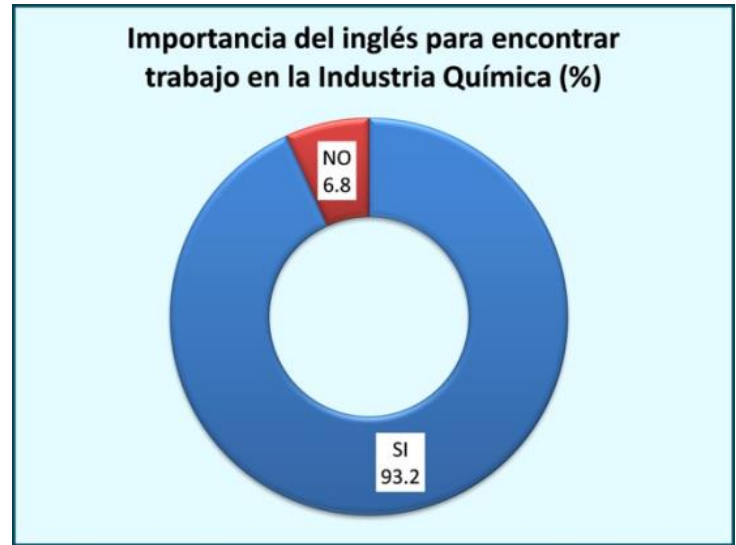

Figura 21. Porcentaje de importancia del inglés para encontrar trabajo en la industria química (diagrama de sectores).

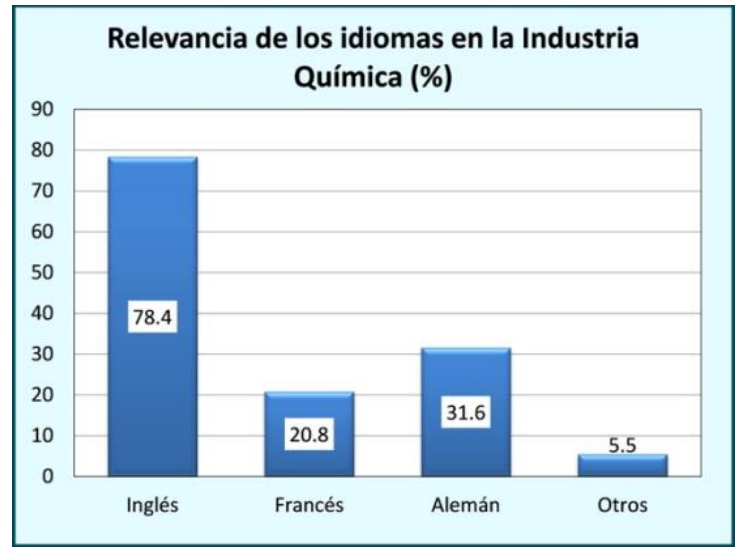

Figura 22. Porcentajes de relevancia de los idiomas en la industria química (diagrama de barras).

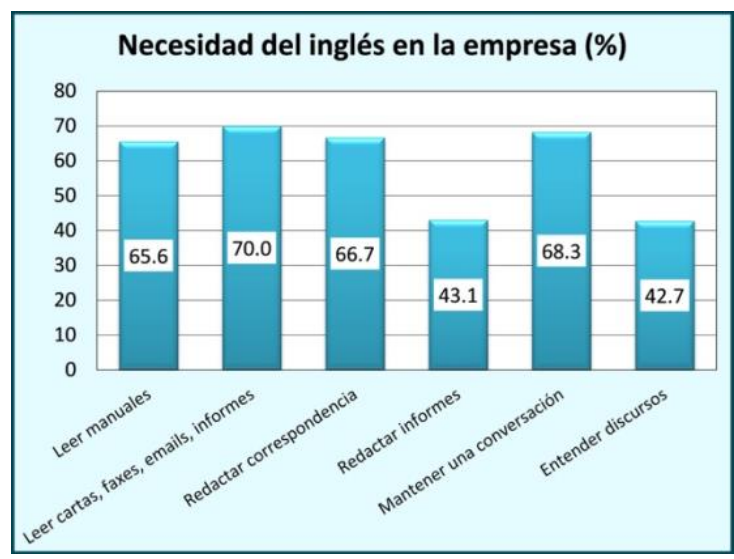

Revista de Lenguas para Fines Específicos 25.1

ISSN: 2340-8561 
Figura 23. Porcentajes de necesidades del inglés en las empresas (diagrama de barras).

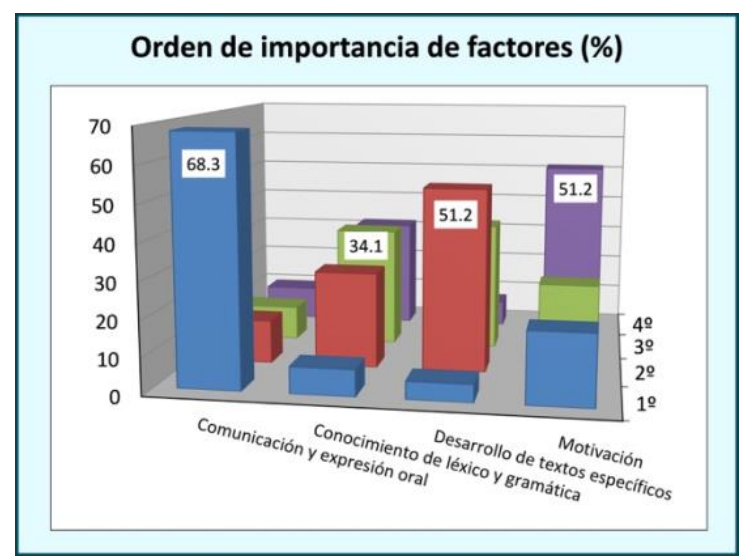

Figura 24. Porcentajes del orden de importancia de diversos factores del inglés (diagrama de barras).

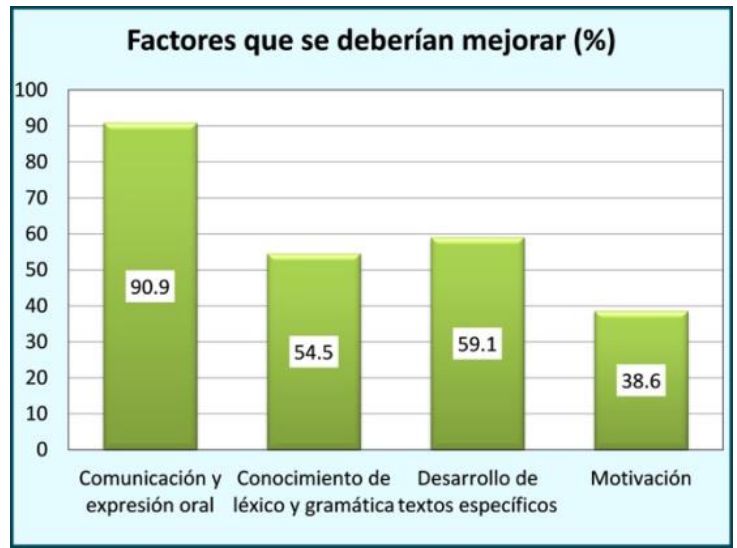

Figura 25. Porcentajes de los factores del inglés a mejorar (diagrama de barras).

\begin{tabular}{|l|l|}
\hline Datos & $\begin{array}{l}- \text { Certificación externa. Se confía mayoritariamente esta acción a la } \\
\text { Escuela Oficial de Idiomas. } \\
- \text { No obstante queda también reconocidas las certificaciones desde } \\
\text { Cambridge ESOL Examinations, así como Trinity College London. }\end{array}$ \\
\hline Índices & $\begin{array}{l}- \text { Se valora la acción formativa en lengua inglesa de forma } \\
\text { regularizada y continuada, siguiendo la estructura de curso } \\
\text { académico; no obstante, se considera fundamental la realización de } \\
\text { cursos monográficos. }\end{array}$ \\
\hline
\end{tabular}

Tabla 14. Generalidades y rasgos comunes: Certificación externa de inglés que tienen las empresas. 


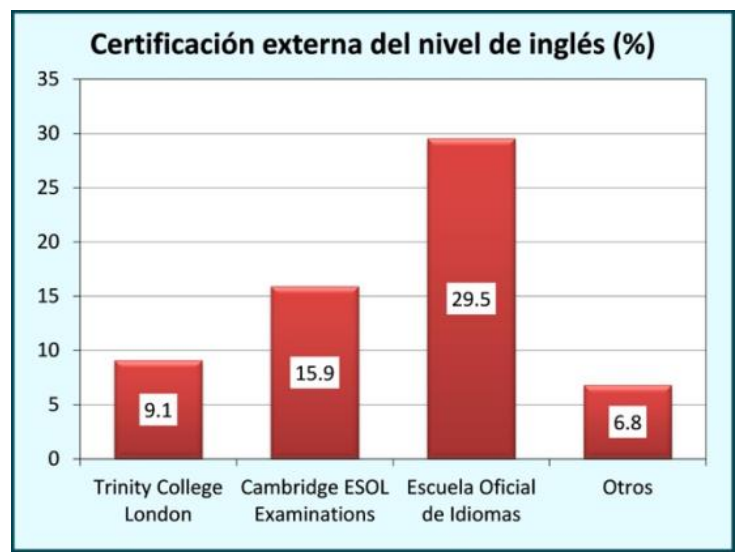

Figura 26. Porcentajes de certificación externa de inglés que tienen las empresas (diagrama de barras).

Del estudio de los datos obtenidos en el Cuestionario 1 podemos inferir los siguientes resultados:

- El mayor número de trabajadores cuyo requisito de perfil de puesto requiere del conocimiento de la lengua inglesa pertenece a los departamentos: Compras, Ventas, Administración e I+D+I, con un común índice promedio del $41 \%$. El Análisis y Control supone un $36 \%$ y bastante alejado de estos índices, Producción y Formación están en el 12\%. Es preciso indicar también, que el rango dispersivo es tan elevado, dependiendo del subsector de que se trate, que puede llegar a $\sigma=22-45 \%$, dependiendo del tipo de departamento a estudio.

- Los subsectores denominados 'Farmaquímica' y 'Productos químicos básicos' son los más exigentes en lo que a formación en lengua inglesa se refiere.

- El nivel de conocimiento medio necesario es el de 'Independiente' con casi el 50\%. Los niveles 'Básico' y 'Muy competente', aparecen muy próximos al $25 \%$ cada uno.

- El volumen de negocio reservado al comercio en lengua inglesa, presenta un amplísimo rango: de 0\% (con una frecuencia del 10\%) a $85-95 \%$ (con una frecuencia del $7 \%$ ). La media considerablemente representativa es de $33,64 \%$, con una desviación estándar $\sigma=29 \%$.

- De todas las respuestas procesadas, sólo un 4,5\% dice no disponer de acreditación alguna; el 95,5\% restante constituyen organizaciones y empresas productoras que trabajan bajo normas de Calidad general y/o específicas del subsector productivo, enfatizando de manera especial en la Buenas Prácticas de Producción y de Control. En menor medida aparecen organizaciones vertebradas siguiendo criterios objetivos establecidos en Sistemas de Gestión Ambiental así como Programas de Gestión de Riesgos Laborales.

- Los viajes por razones de negocios con destino a países en que es necesario el uso de la lengua inglesa, arrojan una media de 30 viajes/año, destacando como en otras facetas una elevada dispersión: 0 viajes en un $30 \%$ de respuestas a 500 viajes en un $3 \%$ de respuestas, por tanto cabe esperar elevada $\sigma=83$.

- Es respuesta casi unánime señalar que el uso de la lengua inglesa a medio plazo tendrá un índice mayor para poder adaptarse a las exigencias del mercado transfronterizo.

- La redacción de documentos escritos en lengua inglesa (Informes, Facturas, Presupuestos, Correos diversos, ...) constituye un 33\% (de media) del computo total de documentos redactados en la empresa. Es característico un amplio rango: $\sigma=30 \%$.

- El uso hablado del idioma inglés en entrevistas personales y contactos telefónicos se entiende una actividad 
social en relación con el trabajo cotidiano con una incidencia de casi el $30 \%$ vía telefónica y un $20 \%$ a través de entrevistas personales. Sólo un $18 \%$ de las respuestas asigna al idioma inglés una incidencia nula en su operatividad empresarial.

- En torno al $70 \%$ de respuestas señalan disponer de página web en lengua inglesa.

- En el uso cotidiano de la lengua inglesa se le atribuye importancia de primer orden a la Motivación así como al Léxico y al conocimiento de Estructuras Gramaticales. Se considera, no obstante, que se deberían propiciar mejoras, a través de acciones específicas que favorezcan sobre todo, la Comunicación y Expresión Oral y en menor medida el Léxico, las Estructuras Gramaticales y desarrollo de textos específicos (Correspondencia y Redacción de Informes).

- La certificación externa de nivel logrado queda mayoritariamente confiada a la Escuela Oficial de Idiomas, observándose en algunos casos la certificación de Cambridge ESOL Examinations.

- El $66 \%$ de las respuestas asegura disponer de un programa anual de formación, oferta formativa para los empleados. La mayor parte de estos programas formativos están enfocados a cursos y seminarios de corta duración cuyos objetos de estudio son, por una parte, temas troncales relacionados con la actividad operativa de la empresa y otros de contenidos claramente transversales: PRL (Prevención de Riesgos Laborales), Calidad y Sistema de Gestión Ambiental. Sólo el 17,6\% de las empresas con programa de formación implementa alguna acción formativa enfocada al conocimiento de la lengua inglesa; estos es, sólo un 11.6 del universo.

- La oferta formativa externa se aprecia sólo en un $66 \%$ de respuestas. Por otra parte, todas las respuestas encuentran necesaria una oferta formativa más amplia, tanto en nivel de conocimiento, como en diversidad de horarios y contenidos orientados a IFE y idioma perfil coloquial y doméstico. Señalar por otra parte, que el $30 \%$ de las respuestas a estas cuestiones manifiesta que la oferta formativa es del todo insuficiente, asignándole valores indicadores de 0 sobre 3 .

- De los subsectores analizados, se encuentran necesidades formativas en los niveles 2 y 3 asociados a un determinado certificado profesional y ocupación, debido a la creciente complejidad de las tareas a realizar en la empresa, cada vez más necesitadas del dominio de la lengua inglesa. No se aprecia necesidad en el nivel 1 por el propio ámbito de la ocupación, mucho más elemental que el 2 o el 3.

- En la búsqueda de empleo, se considera bagaje técnico imprescindible para demostrar competencia suficiente, complemento de la competencia técnica específica, el dominio acreditado de la lengua inglesa. Una carencia o insuficiencia en este sentido pondría a la persona desempleada en la incapacidad para el logro del empleo y desempeño del oficio.

- En el ejercicio y la actividad laboral del sector químico, es condición necesaria el conocimiento medio-alto de la lengua inglesa.

- La oferta formativa actual para atender tal necesidad, se considera del todo insuficiente.

- Se estima que el momento socio laboral actual, es del todo coyuntural, apuntando como previsible un resurgimiento del sector a medio plazo, paralelo y coincidente con las previsiones sociopolíticas europeas para todos los sectores productivos. Por tanto, se espera una generosa oferta formativa para atender estas expectativas en los años próximos.

- Queda reconocido el valor de una Certificación Externa del nivel conseguido.

- Procedería programar acciones formativas en cursos (niveles B1, B2, C1 y C2, preferentemente).

- Se sugiere programar acciones formativas en cursos dirigidos a trabajadores en activo de manera que permitan revalidar y complementar sus conocimientos de la lengua inglesa. 
- Se estima una media de 1/32 la relación Nºmpleos Industria Química/Nºmpleos Mercado Laboral General. Este coeficiente puede ayudar a establecer el número de acciones formativas en lengua inglesa dirigidas al sector químico.

- La frecuencia en los desplazamientos internacionales, aconseja la promoción de acciones formativas en inglés.

- Es necesaria la formación de léxico especializado.

3.2 Cuestionario 2: Encuesta web para determinar las necesidades de formación en inglés fuera del ámbito de FEIQUE

Los datos del cuestionario 2, que contiene las misma preguntas que el 1, se obtuvieron a partir de una encuesta personal realizada en diversos subsectores fuera del ámbito de FEIQUE, tales como: empresas (técnicos y personal de recursos humanos), asociaciones profesionales (secretarios técnicos y personal de formación), institutos tecnológicos (directivos y personal de formación), docentes (profesores universitarios cuya línea de investigación es afín a estas áreas laborales), sondeos telefónicos a empresas y escrutinio de páginas web de empresas. Dicha encuesta se realizó a 6 empresas, 7 asociaciones profesionales y 2 institutos tecnológicos. Todas las respuestas recibidas han sido tratadas, estimándose entre un 7 y un 10\% del universo. En total se han evaluado los datos procedentes de 41 encuestas. Los datos relativos a las características identificativas de las empresas han servido para incluirla dentro de una de las cinco áreas de la familia profesional de química (Análisis y control. Proceso químico, Transformación de polímeros, Pasta, papel y cartón y Farmaquímica). Las respuestas recibidas proceden en su mayor parte de las comunidades autónomas de Murcia, Valencia, Aragón y, en lo que se refiere a asociaciones de ámbito nacional, Madrid.

A continuación aparecen los valores promedios de las respuestas a los distintos ítems planteados en el cuestionario expresados por las ocupaciones principales.

\subsubsection{Cuestionario 2: Área de Análisis y control. Comentarios:}

- La formación en lengua inglesa se considera muy relevante.

- Las expectativas a medio plazo sobre necesidad de ampliación de puestos que conlleven dotación específica en lengua inglesa es del $142 \%$, esto es, el índice corrector es $f=1.42$.

- Los departamentos de Administración y Comercial (Compras y Ventas) requieren de mayor dotación de personal con conocimiento en lengua inglesa.

- El rango de documentos elaborados en lengua inglesa ofrece una gran dispersión, siendo abundantes en las áreas de ensayos químicos y biotecnológicos, y escasos en los ensayos de naturaleza física.

- Se dispone de página web en lengua inglesa de forma casi unánime.

- Los departamentos de Administración y Comercial (Compras y Ventas) requieren de un conocimiento medio/avanzado en lengua inglesa.

- La oferta formativa interna es prácticamente inexistente.

- Como media, si bien la dispersión es importante entre las distintas áreas, en torno al $20 \%$ de los trabajadores 
requieren formación específica en lengua inglesa.

\subsubsection{Cuestionario 2: Área de Proceso químico. Comentarios:}

- Área de la familia en que la formación en lengua inglesa se considera muy relevante.

- Las expectativas a medio plazo sobre necesidad de ampliación de puestos que conlleven dotación específica en lengua inglesa es del $147 \%$, esto es, el índice corrector es $f=1.47$.

- Los departamentos de Administración y Comercial (Compras y Ventas) requieren de mayor dotación de personal con conocimiento en lengua inglesa.

- Se dispone de página web en lengua inglesa.

- Entre 15 y $35 \%$ de documentos se redactan en lengua inglesa.

- Departamentos de Administración y Comercial (Compras y Ventas) requieren de un conocimiento medio/avanzado en lengua inglesa.

- La oferta formativa interna es insuficiente, si bien alcanza en torno al $40 \%$ de las necesidades previstas.

- En torno al 25\% de los trabajadores requieren formación específica en lengua inglesa.

\subsubsection{Cuestionario 2: Área de Transformación de polímeros. Comentarios:}

- Área de la familia en que la formación en lengua inglesa se considera muy relevante.

- Las expectativas a medio plazo sobre necesidad de ampliación de puestos que conlleven dotación específica en lengua inglesa es del $175 \%$, esto es, el índice corrector es $f=1.75$.

- Los departamentos de Administración y Comercial (Compras y Ventas) requieren de mayor dotación de personal con conocimiento en lengua inglesa.

- Se dispone de página web en lengua inglesa.

- Entre 35 y $45 \%$ de documentos en lengua inglesa.

- Departamentos de Administración y Comercial (Compras y Ventas) requieren de un conocimiento avanzado en lengua inglesa.

- La oferta formativa interna es prácticamente inexistente.

- En torno al 30\% de los trabajadores requieren formación específica en lengua inglesa.

\subsubsection{Cuestionario 2: Área de Pasta, papel y cartón. Comentarios:}

- Área de la familia en que la formación en lengua inglesa se considera de menor relevancia.

- Las expectativas a medio plazo sobre necesidad de ampliación de puestos que conlleven dotación específica en lengua inglesa es del $134 \%$, esto es, el índice corrector es $f=1.34$.

- En general, la fabricación y preparación de pastas, requiere de un mayor conocimiento de la lengua inglesa, si bien, la incidencia es mucho menor que en otras áreas de la familia.

- Dentro de la heterogeneidad de las respuestas, cabe resaltar, sin embargo, la tendencia común de toda el 
área a incluir a los departamentos de Administración y Comercial (Compras y Ventas) como los más dotados de personal con conocimiento en idioma inglés.

- Se dispone de página web en lengua inglesa.

- Entre 10 y $20 \%$ de documentos en lengua inglesa.

- Departamentos de Administración y Comercial (Compras y Ventas) requieren de un conocimiento básico o competencia media en lengua inglesa.

- La oferta formativa interna es escasa.

- En torno al 13-15\% de los trabajadores requieren formación específica en lengua inglesa.

\subsubsection{Cuestionario 2: Área de Farmaquímica. Comentarios:}

- Área de la familia en que se estima necesaria la formación en lengua inglesa.

- Las expectativas a medio plazo sobre necesidad de ampliación de puestos que conlleven dotación específica en lengua inglesa es de $144 \%$ a $166 \%$.

- No hay homogeneidad en lo que a necesidades de formación en lengua inglesa se refiere; el rango interempresarial es muy amplio, produciéndose una importante dispersión.

- Se dispone de página web en lengua inglesa.

- Uso cotidiano de anglicismos.

- Elevado índice en la elaboración de documentos en lengua inglesa.

- Departamentos de Administración y Comercial (Compras y Ventas) requieren de un conocimiento avanzado en lengua inglesa.

- Departamentos de Control de Calidad e I+D+I, requieren de alto nivel de conocimiento en lengua inglesa, incidiendo especialmente en la lectura comprensiva y en la redacción y lectura de informes, manuales, etc.

- Producción es el departamento menos exigente, reservando un porcentaje de uso de la lengua inglesa menor, si bien con el mismo grado de competencia.

- La oferta formativa interna es virtualmente nula, confiando esta faceta al propio trabajador.

- En torno al $49 \%$ de los trabajadores requieren formación específica en lengua inglesa.

- La oferta formativa externa parece no satisfacer las necesidades de trabajadores en expectativas de empleo ni trabajadores en activo.

\subsubsection{Escrutinio de páginas web de empresas de las diferentes áreas.}

Además de la encuesta del Cuestionario 2, se han escrutado páginas web de empresas de los subsectores que componen la actividad laboral. También se han analizado los Programas Anuales de Formación de las Asociaciones/ Agrupaciones de empresas, para atender las necesidades formativas de los trabajadores. De este estudio se observa que la oferta formativa de los distintos subsectores recae sobre las correspondientes asociaciones, reservándose las empresas la programación de algunas acciones formativas excepcionalmente, y de naturaleza muy selectiva. Generalmente se trata de cursos 
monográficos programados y auspiciados por las Asociaciones empresariales, si bien, frecuentemente organizados e impartidos por empresas contratadas para tal efecto en las que la acción queda delegada. Los cursos previstos en los programas anuales de formación, incluyen materias a estudio consideradas troncales, propias del subsector de que se trata y materias de naturaleza transversal, típicamente: Prevención de Riesgos laborales, Calidad, Informática e Idiomas. De catorce Asociaciones escrutadas y tres Centros Tecnológicos, sólo una Asociación (AFCO), ofrece a los trabajadores de las empresas asociadas formación complementaria en idioma inglés, en los tres niveles de competencia considerados (básico, medio y avanzado), constituyendo sólo 1/22 (4.54\%) de la propuesta formativa de esa asociación. Las otras Asociaciones no incluyen actividad formativa alguna en esta disciplina.

\section{Conclusiones y recomendaciones}

A la luz de los datos primarios obtenidos, se puede concluir:

- De los subsectores analizados, se encuentran necesidades formativas en los niveles 2 y 3 asociados a un determinado certificado profesional y ocupación, debido a la creciente complejidad de las tareas a realizar en la empresa, cada vez más necesitadas del dominio de la lengua inglesa. No se aprecia necesidad en el nivel 1 por el propio ámbito de la ocupación, mucho más elemental que el 2 o el 3.

- En la búsqueda de empleo, se considera bagaje técnico imprescindible para demostrar competencia suficiente, complemento de la competencia técnica específica, el dominio acreditado de la lengua inglesa. Una carencia o insuficiencia en este sentido pondría a la persona desempleada en la incapacidad para el logro del empleo y desempeño del oficio.

- En el ejercicio y la actividad laboral del sector químico, es condición necesaria el conocimiento medio-alto de la lengua inglesa. Cualquier otro idioma empleado en las relaciones inter-empresariales transfronterizas no alcanza más allá del $25 \%$ del uso en lengua inglesa.

- La oferta formativa actual para atender tal necesidad, se considera del todo insuficiente, por lo que procedería potenciar la acción formativa, auspiciada desde las instituciones públicas.

- Se estima que el momento sociolaboral actual, es del todo coyuntural, apuntando como previsible un resurgimiento del sector a medio plazo, paralelo y coincidente con las previsiones sociopolíticas europeas para todos los sectores productivos. Por tanto se espera una generosa oferta formativa para atender estas expectativas en los años próximos.

- Queda reconocido el valor de una Certificación Externa del nivel conseguido, en especial si se trata de personal laboral bien cualificado que ejercen o pueden ejercer su actividad laboral en empresas acreditadas bajo normas universales como UNE-EN-ISO 9001, UNE-EN-ISO 17025 y otras.

- Procedería programar acciones formativas en cursos dirigidos a desempleados (niveles B1, B2, C1 y C2, preferentemente).

- Se sugiere programar acciones formativas en cursos dirigidos a trabajadores en activo de manera que permitan revalidar y complementar sus conocimientos de la lengua inglesa para la próxima década en un número mayor de 10.000 alumnos/año en todo el territorio nacional.

- Se estima una media de 1/32 la relación No Empleos Industria Química/No Empleos Mercado Laboral General. Este coeficiente puede ayudar a establecer el número de acciones formativas en lengua inglesa dirigidas al sector químico. 
- La frecuencia en los desplazamientos internacionales, y aceptado mayoritariamente el inglés como vehículo comunicativo, aconseja la promoción de acciones formativas encaminadas al apoyo lingüístico en sus facetas coloquiales.

- El uso en el argot de la industria química de expresiones, giros, acrónimos y terminología derivada de anglicismos, plantea la necesidad de acciones formativas de carácter específico dirigido a trabajadores activos y potenciales del sector químico.

La siguiente fase del estudio es la implementación de una oferta formativa, basada en el análisis de la necesidad detectada en el estudio, así como en la evaluación de los resultados obtenidos en esta propuesta formativa.

\section{About the author}

Nicolás Montalbán es Doctor por la Universidad de Murcia y Master en Inglés para Fines Específicos y Profesionales por la UNED. Es actualmente profesor asociado en el Departamento de Traducción e Interpretación de la Universidad de Murcia, donde ha impartido docencia fundamentalmente en las asignaturas de Traducción para el Turismo y el Ocio y Traducción especializada (Tecnología, Empresa, Geografía, Jurídica, Científico- 
Técnica, etc.). Su campo de investigación actual es el Inglés para Fines Específicos, siendo investigador principal de un grupo de investigación promovido por el Servicio Público de Empleo Estatal sobre Necesidades de Formación y Cualificación en Lengua Inglesa en la Familia Profesional de Químicas, del que hay ya un primer Estudio Sectorial de Necesidades de Formación y Cualificación en Lengua Inglesa en la Familia Profesional de Química, así como las Pruebas de Diagnóstico dirigidas a comprobar la competencia clave en comunicación en lengua inglesa de nivel 2 y 3 para el Servicio Regional de Empleo y Formación de la Comunidad Autónoma de la Región de Murcia. Ha colaborado con el grupo de investigación ATLAS (Applying Technology to Languages) de la UNED en el proyecto de investigación eLITE (Edición Literaria Electrónica), y en el proyecto MOONLITE (Massive Open Online courses eNhancing Linguistic and Transversal skills for social inclusion and Employability). Ha sido docente de cursos de Inglés para Química, Inglés para Control de Calidad y Laboratorio Químico, Inglés para Ingeniería, en el Centro de Referencia Nacional de Química de Cartagena, centro en el que ha colaborado en Proyectos Europeos de Formación, así como en la traducción (inglés-español), de Guías Didácticas y Manuales de Estudio de Ensayos No Destructivos, niveles I, II y III, de Ensayos no Destructivos, en los métodos de Líquidos Penetrantes, Partículas Magnéticas, Ultrasonidos, Corrientes Inducidas y Radiografía Industrial, del proyecto piloto "PROQUALINDT" del Programa Europeo de Formación Profesional "Leonardo da Vinci". Ha impartido docencia en lengua inglesa y trabajado como profesor durante más de veinte años en IFE y educación secundaria, así como en empresas privadas dedicadas al comercio marítimo internacional. Ha publicado artículos sobre: La recepción de Shakespeare en Murcia y Cartagena en el siglo XIX; El teatro en el aula, un instrumento de aprendizaje de lenguas extranjeras; El uso de OCW y wikis como herramienta colaborativa para la traducción especializada; El Estudio Sectorial de formación y cualificación en lengua inglesa y El uso de herramientas TAO en textos científicos y turísticos.

\section{Acknowledgements}

Centro de Referencia Nacional de Química de Cartagena.

\section{References}


Anthony, L. (2014). AntConc help manual (v.002). <http://www.laurenceanthony.net/software/antconc/releases/ AntConc344/help.pdf> [17/4/2019].

Basturkmen, H. (2010). Developing Courses in English for Specific Purposes. Hampshire: Palgrave Macmillan.

Cobb, T. (2015). Complete lexical tutor. <http://www.lextutor.ca/> [17/4/2019].

Crystal, D. (1995). The Cambridge encyclopedia of the English language. Cambridge: Cambridge University Press.

Dudley-Evans, T. and St. John, M.J. (1998). Developments in English for Specific Purposes. A multidisciplinary approach. Cambridge: CUP.

FEIQUE, Federación Empresarial de la Industria Química Española. (2019). <https://www.feique.org/> [17/4/2019].

Hadley, J., (2006). Needs analysis in ESP. In: English for specific Purposes in the Arab World (Lahlou, M S; Richardson, A), eds; TESOL Arabia. Dubai. Pp. 3-6.

Heatley, A., Nation, I. S. P., \& Coxhead, A. (2002). Range [Computer software]. . <http://www.victoria.ac.nz/lals/staff/ paulnation/nation/aspx> [17/4/2019].

Hsu, W. (2014). Measuring the vocabulary load of engineering textbooks for EFL undergraduates. ESP in Asia, 33, 54-65. $<$ https://doi.org/10.1016/j.esp.2013.07.001>[17/4/2019].

Kanoksilapatham, B. (2015). Distinguishing textual features characterizing structural variation in research articles across three engineering sub-discipline corpora. English for Specific Purposes, 37, 74-86. <https://doi.org/10.1016/j.esp2014.06.008>[17/4/2019].

Kwary, D. A. (2011). A hybrid method for determining technical vocabulary. System, 39, 175-185. <https://doi.org/10.1016/j.system.2011.04.003>[17/4/2019].

Liu, J.Y., Chang, Y.J., Yang, F.Y., and Sun Y.C. (2011). Is what I need what I want? Reconceptualising college students' needs in English course for general and specific/academic purposes. Journal of English for Academic Purposes. Vol. 10, 271280.

Mackay, R.; Mountford, A. J. (1978). The teaching of English for Specific Purposes: theory and practice. in: English for Specific Purposes: A case study approach. (Mackey, R.; Mountford A.J.), eds; Longman. London

Nunan, David (2004). Task-Based Learning Teaching. Cambridge: Cambridge University Press.

Piqué, J., Estevez, N. y Viera, D.J. (1994). English in the Health Sciences: Focus on the selections and design of materials, en Mateo Martínez, J., Guillén Nieto, V. y Moody, B. (Eds.). English for Specific Purposes: Approaches and Strategies. Alicante. Universidad de Alicante. Departamento de Filología Inglesa, Working Papers, Vol. 3, pp.53-63.

Robinson, P. (1991). ESP Today: A practitioner's guide. New York: Prentice Hall.

Rowley-Jolivet, E. (2015). Quantification in conference talks and proceedings articles in engineering. English for Specific Purposes, 38, 11-22. <https://doi.org/10.1016/j.esp.2014.10.003>[17/4/2019].

Spence, P., \& Liu, G. (2013). Engineering English and the high-tech industry: A case study of an English needs analysis of process integration engineers at a semiconductor manufacturing company in Taiwan. English for Specific Purposes, 32, 97-109. <https://doi.org/10.1016/j.esp.2012.11.003>[17/4/2019].

Sysoyev, P. V. (2000). Developing an English for specific purposes course using a learner centered approach: a Russian experience. The Internet TESL Journal 6 (3). <http://iteslj.org/Techniques/Sysoyev-ESP.html>[17/4/2019].

Todd, R. W. (2017). An opaque engineering word list: Which words should a teacher focus on? English for Specific Purposes, 45, 31-39. <https://doi.org/10.1016/j.jeap.2016.08.003>[17/4/2019].

Trimble, L. (1990). English for Science and Technology. Cambridge: CUP. 
Ward, J. (2009). A basic engineering English word list for less proficient foundation engineering undergraduates. English for Specific Purposes, 28, 170-182. <https://doi.org/10.1016/j.esp.2009.04.001>[17/4/2019].

Widdowson, H.G. (1978). Teaching Language as Communication. Oxford: OUP. 